\title{
Gary Victor, Banal oubli
}

\section{Carminella Biondi}

\section{(2) OpenEdition}

\section{Journals}

\section{Edizione digitale}

URL: http://journals.openedition.org/studifrancesi/7754

DOI: 10.4000/studifrancesi.7754

ISSN: 2427-5856

\section{Editore}

Rosenberg \& Sellier

\section{Edizione cartacea}

Data di pubblicazione: 1 décembre 2009

Paginazione: 681

ISSN: 0039-2944

\section{Notizia bibliografica digitale}

Carminella Biondi, «Gary Victor, Banal oubli», Studi Francesi [Online], 159 (LIII | III) | 2009, online dal 30 novembre 2015, consultato il 08 janvier 2021. URL: http://journals.openedition.org/studifrancesi/7754 ; DOI: https://doi.org/10.4000/studifrancesi.7754

Questo documento è stato generato automaticamente il 8 janvier 2021.

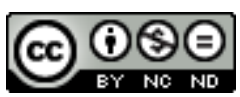

Studi Francesi è distribuita con Licenza Creative Commons Attribuzione - Non commerciale - Non opere derivate 4.0 Internazionale. 


\title{
Gary Victor, Banal oubli
}

\author{
Carminella Biondi
}

\section{NOTIZIA}

GARY VICTOR, Banal oubli, La Roque d'Anthéron, Vent d'ailleurs, 2008, pp. 190.

1 Con questo romanzo Gary Victor continua a percorrere con esiti felicissimi quel particolare filone letterario che, utilizzando canoni di riferimento conosciuti, si può definire noir, ma che fonde in realtà le più svariate tipologie del genere narrativo. Che ci troviamo di fronte ad un enigma, o meglio a un caso complicato da risolvere, emerge fin dalla copertina, dove compaiono due autori e due titoli diversi: scritto in grande, in nero, l'autore e il titolo veri, sotto, un po' più in piccolo e in bianco, un secondo autore che si chiama Pierre Jean ed un secondo titolo Nuit muette sur la croix de l'arc-en-ciel. Ad imbrogliare ulteriormente le piste, sempre in copertina in guisa di fascetta ma parte integrante della copertina stessa, una dichiarazione sorprendente: «Moi, Gary VICTOR, réaffirme être le seul auteur de l'ouvrage BANAL OUBLI, ce à toute fin utile et légale». Il romanzo si conclude con due lettere degli «autori» all'editore in cui entrambi rivendicano la paternità dell'opera. Dunque l'oggetto del contendere e quindi il caso da risolvere per il già noto ispettore Dieuswalwe Azémar sembrerebbe essere il furto di proprietà letteraria, in realtà nel corso della storia ci renderemo conto che il caso, che provoca anche delle vittime, è molto più complicato e difficile: si tratta della ribellione del personaggio, uno scrittore di nome Pierre Jean, che contesta la dittatura dello scrittore - degli scrittori in senso lato - e vuole riprendersi la paternità del racconto, utilizzando proprio la devise del padre dello scrittore, che ritorna come un leit-motiv nel corso di tutta la storia: «Vainqueur ou vaincu, ne laisse à quiconque, pas même à Dieu, le soin d'écrire ton histoire». L'indagine poliziesca, che pure è rigorosamente e seriamente condotta, è in realtà il pretesto per porre, sul piano letterario, il problema dello statuto dello scrittore e della sua autonomia in rapporto ai suoi personaggi, ma soprattutto, come in tutti i romanzi di Victor, per farci penetrare nell'intricata e 
incredibile realtà haitiana, lungo un percorso allo stesso tempo divertente $\mathrm{e}$ drammatico. 